\title{
NON-LINEAR ANALYSIS OF SLENDER MASONRY COLUMN SUBJECTED TO BIAXIAL BENDING
}

\author{
MareK VoKÁL*, Michal Drahorád \\ Czech Technical University in Prague, Faculty of Civil Engineering, Department of Concrete and Masonry \\ Structures, Thákurova 7, 16629 Prague, Czech Republic \\ * corresponding author: marek.vokal@fsv.cvut.cz
}

\begin{abstract}
The article deals with a method for analysing slender masonry columns. The proposed method uses material and geometric non-linearity. Various stress-strain diagrams can be used: linear, linear-plastic, parabolic-plastic, two various parabolic and rigid-plastic. In all cases, the tensile strength is neglected. The method can be used for analysing the column in accordance with Eurocodes in two ways: SLS (serviceability limit state) and ULS (ultimate limit state). The internal forces are calculated on a general beam model, with imperfections in both directions, which result in two bending moments in two perpendicular planes - biaxial bending. This case is not covered by the current code - Eurocode, even though all columns are more or less loaded in both directions. In this numerical study, using Matlab software, an algorithm was developed for modelling a real 3D case. The results of this study are also compared to the results of laboratory tests of masonry columns.
\end{abstract}

KEYWORDS: Non-linearity, masonry, column, stress-strain diagram.

\section{INTRODUCTION}

In general, all structures are loaded in both directions and all material behaviour is precisely described by the non-linear behaviour. In practical structural design, the stiffness of an element usually permits the smaller load effect to be neglected and to consider the element loaded in one direction only. It is not suitable for cases, for which $M_{y}>0.1 M_{z}$ (or $M_{z}>0.1 M_{y}$ ), such as columns in a corner of a building, where load by wind can occur in two directions or, for example, of a high bridge pier, where the transverse wind load cannot be neglected. The impact of the biaxial loading is even higher in the case of slender columns. According to the current code of masonry structures ([1]), the rectangular cross section loaded by a combination of normal force and one bending moment (which results in a smaller, also rectangular cross section, if the rigid-plastic stress-strain diagram is considered) can be considered. This is not sufficient for the case of biaxial bending moments, which can lead to a skewed neutral axis and trapezoidal or general polygon-shaped cross section. The general stress diagram depicting biaxial bending is shown in Figure 1 for the case the SLS and in Figure 2 for the case of the ULS (an example of a rigid-plastic diagram). The stressstrain diagram for the SLS is clearly linear for the compression, but for the ULS, there are many options. The [1] recommend a non-linear relation, even though it doesn't recommend which relation should be used. Another possibility is to use an elastic - ideal plastic. The equation for the check of design value of resistance normal force arises from the rigid-plastic diagram, which is also used in this article. See all the used diagrams in chapter 3

\section{Methods AND Literature ReVieW}

The biaxial bending is mentioned in few masonry standards throughout the world. In case that the biaxial bending is mentioned, the verification is very conservative. For example, according to the British standard $-\left[2\right.$, the slenderness ratio $\lambda_{s}$ is limited by the value of 27 (in this study, columns of ratio $\lambda_{s}$ up to value of 300 are analysed). All the methods consider only a rectangular shape of the cross section. In general, methods can be divided by (each method has its shortcut):

- Consideration of material non-linearity for the calculation of internal forces.

$\triangleright$ Yes $(\mathrm{M})$

- Linear stress-strain diagram (L)

- Rigid-plastic diagram (R)

- Non-linear diagram $(\mathrm{N})$

$\triangleright$ No (-)

- Consideration of geometric non-linearity for the calculation of internal forces.

$\triangleright$ Yes $(\mathrm{G})$

$\triangleright$ No $(-)$

- Method, according to which the check is done.

$\triangleright$ Effective area - rectangular shape, 1 coefficient for the impact of buckling (B1)

$\triangleright$ Effective area - rectangular shape, 2 coefficients for the impact of buckling (B2)

$\triangleright$ Effective area - general shape according to B. Das [3], 1 coefficient for the impact of buckling (D)

$\triangleright$ Fully non-linear calculation, controlling the strain and stress of the material (S) 


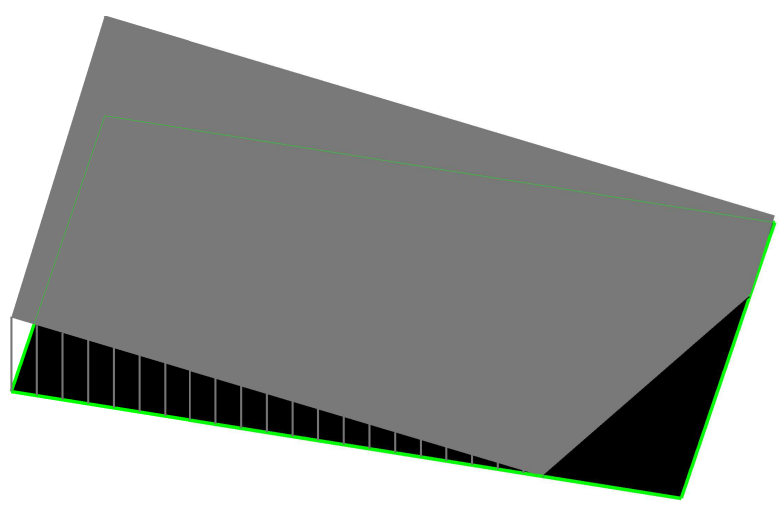

Figure 1. The general stress diagram of a rectangular cross section - SLS.

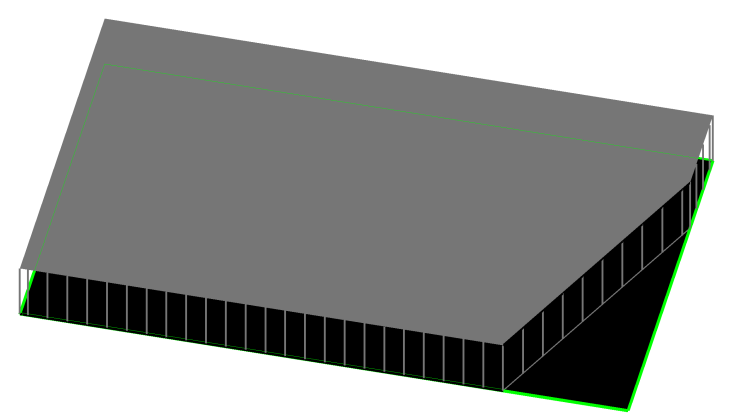

Figure 2. The general stress diagram of a rectangular cross section in ULS - an example of a rigid-plastic stress-strain diagram.

For example, the method proposed by this article is ML,R,N GB1,D,S method ("," means multiple options). The order of characters in the shortcut corresponds to the order of items in the list above. The method of EC6 [1] is -RGB?, see the following chapter.

\subsection{Methods according to EC6 [1]}

According to [1, only the wall should be verified. Biaxial bending is not handled. The eccentricity of the load occurs in just one direction (in the direction of the smaller stiffness). The design normal resistance force must fulfil the following condition:

$$
\begin{gathered}
N_{E d} \leq N_{R d}=\Phi B H f_{d}, \\
\Phi_{i}=1-2 \frac{e_{i}}{B}
\end{gathered}
$$

for the check of the foot and the head of the column, and

$$
\begin{gathered}
\Phi_{m}=A_{1} e^{\frac{-u^{2}}{2}}, \\
A_{1}=1-2 \frac{e_{m k}}{B}, \\
u=\frac{\lambda-0.063}{0.73-1.17 e_{m k} / B},
\end{gathered}
$$

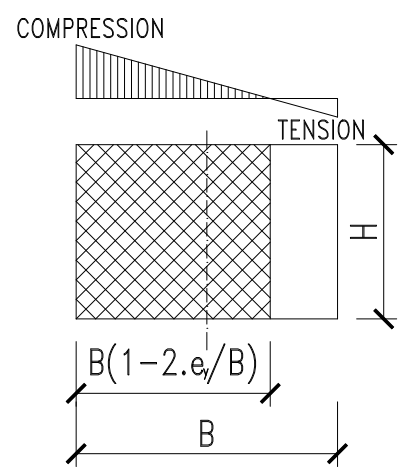

Figure 3. Shape of the cross section due to the load with eccentricity in one direction.

$$
\lambda=\frac{h_{e f}}{B} \sqrt{\frac{f_{k}}{E}},
$$

for the check in the middle of the columns height, where: $N_{E d}$ - design value of applied normal force, $N_{R d}$ - normal resistance force, $\Phi$ - capacity factor according to slenderness, $\Phi_{i}$ at the top or bottom of the column, $\Phi_{m}$ in the middle, $B$ - width of a section, $H$ - thickness of a section, $f_{d}$ - design strength of masonry, $f_{k}$ - characteristic masonry normal strength, $E$ - Young's modulus of elasticity, $h_{e f}$ - critical (buckling) length, $e$ - the base of the natural logarithm, $e_{m k}$ - sum of eccentricities from the load, initial imperfection and creep in the middle of the column, $e_{i}-$ sum of eccentricities from the load, initial imperfection and creep in the head or foot of the column.

This relation considers bending in only one plane, in the ultimate limit state. Serviceability limit state is not handled, no relationship is given. It is generally denoted, that overstressing or damage shall be avoided.

\subsection{JÄGER, W. MAUERWERK-KALENDER}

According to [4], the reduced shape of the cross section has the following shape:

According to [4], the following relation should be used:

$$
\begin{gathered}
N_{R d}=\Phi_{i y} \Phi_{i z} B H f_{d}, \\
\Phi_{i y}=\left(1-2 \frac{e_{y}}{B}\right) e^{\frac{-u_{y}^{2}}{2}}, \\
\Phi_{i z}=\left(1-2 \frac{e_{z}}{H}\right) e^{\frac{-u_{z}^{2}}{2}},
\end{gathered}
$$

where: $u_{y}$ and $u_{z}$ can be calculated according to previous section. $e_{y}$ and $e_{z}$-sum of eccentricities from the load, initial imperfection and creep in the middle of the column in the direction of axes $y$ and $z$, respectively. It is the RGB2 method. The equations consider a rigid-plastic stress-strain diagram and multiply two coefficients of buckling (capacity factors), which is very conservative. 


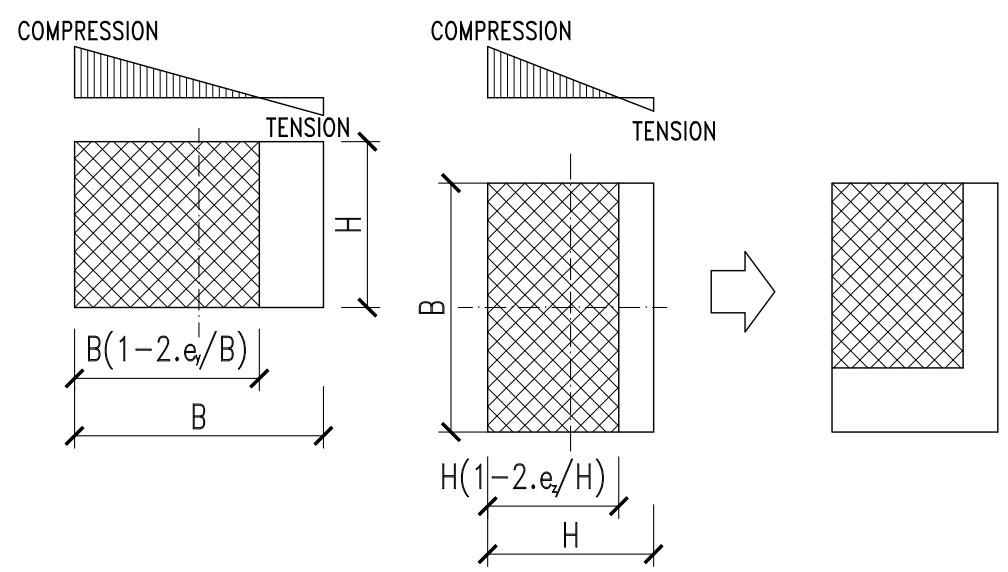

Figure 4. Method, which uses effective area - rectangle shape (shortcut B).

\subsection{VAlENTIN FöRSTER 5}

The method shortcut is -R-B1. The article [5] states, that:

$$
\begin{gathered}
N_{R d}=\min \left(\Phi_{R d, y} B_{\text {red }} H f_{d} ; \Phi_{R d, z} B H_{\text {red }} f_{d}\right), \\
B_{\text {red }}=\left(1-2 \frac{e_{y}}{B}\right) B \\
H_{\text {red }}=\left(1-2 \frac{e_{z}}{H}\right) H,
\end{gathered}
$$

where: $\Phi_{R d, y}$ - slenderness reduction factor in the direction of axis $y$ according to the previous section, $\Phi_{R d, z}$ - slenderness reduction factor in the direction of axis $z$ according to the previous section.

This proposal is based on using the load-bearing capacity of exclusively uniaxially eccentrically loaded compressed members for calculating the load-bearing capacity of biaxially eccentrically loaded compression members. It uses a rigid-plastic stress-strain diagram and just one coefficient of buckling.

\subsection{CAIS, J. AND DAS, B.: SKeW Shape OF COMPRESSED AREA}

Skew shape (shortcut -R-D) using a rigid-plastic stressstrain diagram according to [3] and [6] proposed for the check of the stress in the soil under the rectangular shallow foundations gives us the following relations:

$$
\begin{gathered}
N_{E d} \leq N_{R d}=\Phi A_{e f f} f_{d}, \\
A_{e f f}=\lambda_{D} \beta / 2, \\
\lambda_{D}=3 / 2-3 \epsilon_{x}, \\
\beta=3 / 2-3 \epsilon_{z}, \\
\epsilon_{z}=e_{z} / H, \\
\epsilon_{x}=e_{x} / B,
\end{gathered}
$$

where: $B$ - width of a section, $H$ - thickness of a section, $e_{x}$ - eccentricity in the direction of the dimension $H, e_{z}$ - eccentricity in the direction of the dimension $B$.

These relationships are valid just for the case where the effective area has a triangular shape, see Figure 5. In other cases, the calculation is much more complicated, see [3].

\subsection{ACI - STANDARD OF AMERICAN CONCRETE INSTITUTE}

The method of ACI [7] is described in section 4.2

\section{Method USED IN THIS ARTICLE}

\subsection{ASSUMPTIONS OF ANALYSIS}

On the level of the cross section, the local axes are used: $y \_l o c$ and $x \_l o c$. For forming the global stiffness matrix, the global axes are used: $x_{g}$ and $y_{g}$. Because the tension cannot be carried by the material, cracks open and the loaded part of the cross section, which carries the load, changes its shape. As a consequence, the centroid of the cross section moves. The centroid can, in general, move in both horizontal directions, in the plane of the cross section (according to Figure 7, in direction of $y \_l o c$ and $\left.x \_l o c\right)$. The behaviour of the slender column, when considering the material non-linearity, can be described by Figure 6 .

According to the magnitude of the acting bending moments, the neutral axis can be skewed or, in a special case, perpendicular to one of axes $y \_l o c$ and $x \_l o c$ of the local coordinate system. The special case, for which the neutral axis is parallel to one of the axes and the imperfection in the perpendicular direction is considered zero, is discussed in article 8 .

In general, the following shapes of cross sections can occur:

(1.) Rectangular shape in the case of one bending moment $-M_{y \_l o c}$.

(2.) Rectangular shape in the case of one bending moment $-M_{z_{\text {loc }} \text {. }}$. 


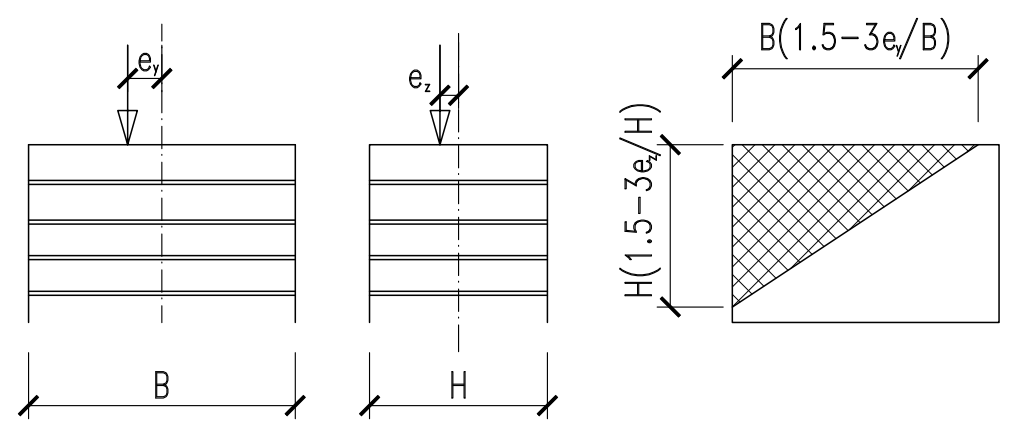

FiguRE 5. Shape of effective compressed area according to 3 .

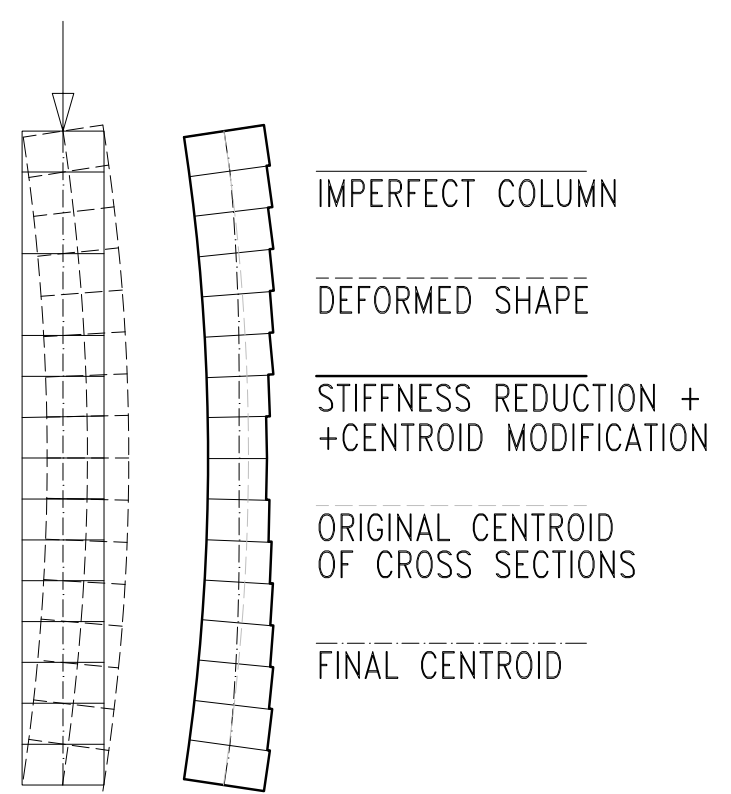

Figure 6. Change of geometry of the column due to material non-linearity.

(3.) General polygon shape, which was created by cutting off one triangle.

(4.) Trapezoidal cross section, where edge $B$ is reduced (see $B, H$ in Figure 3).

(5.) Trapezoidal cross section, where edge $H$ is reduced.

(6.) Triangular shape.

In the proposed algorithm, all cases are covered. If $M_{z \_l o c}<0.1 M_{y \_l o c}$, case \# 1 can be used and if $M_{y \_l o c}<0.1 M_{z \_l o c}$, case \# 2 can be used. The case \# 6 usually results in the collapse of the structure for the case of slender column (see the conclusions of this article). However, it can occur in the case of the short column being loaded by large eccentricities. In this article, the approach to the interaction between the mortar and the masonry units is chosen the same as in the current code [1] - the masonry is homogenized in a suitable manner. According to [9], the method of homogenization used in Eurocode is called "yield line theory" and it is based on labo-
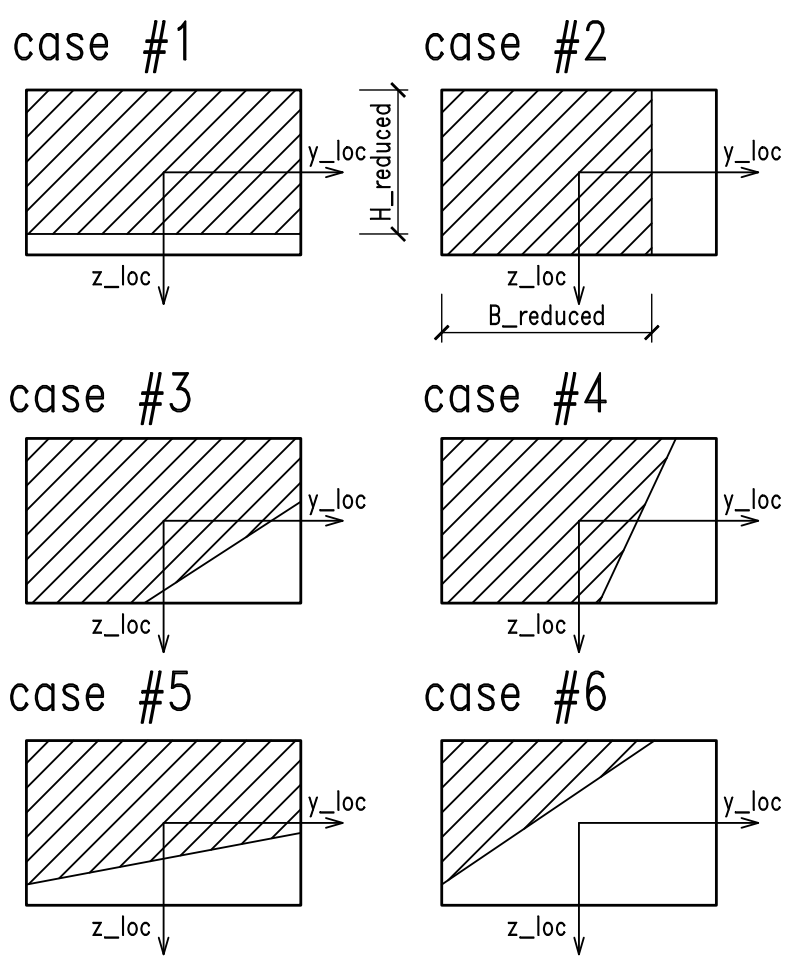

Figure 7. Cases which can occur in the structure.

ratory tests (e.g., [10 and [11]) conducted on brick masonry walls subjected to lateral loads, showing that the failure takes place along a well-defined pattern of lines. In this article, the whole column is considered as a beam from the same material of uniform strength and uniform Young's modulus of elasticity. The shape of the cross section depends on the resulting strain diagram for the appropriate cross section in $i$-th step of the calculation. The tensioned part of the cross section is excluded. The column has an eccentricity (imperfection) in both directions $y \_l o c$ and $z$ _loc. In general, the imperfection in the direction $y_{\text {_l }}$ loc can be independent on the imperfection in the direction $z$ _loc. The imperfection of sin function shape is considered. The buckled shape or eigenvector is described in $[12$. As a boundary conditions, both the top and the bottom of the column are considered hinged, at the bottom, all translations are fixed, at the top, hor- 
izontal translations are fixed, the vertical is free (a simply supported beam).

\subsection{Developed ALGORIThm}

The algorithm considers both step the material nonlinearity and the geometric non-linearity in each step. The geometric non-linearity is handled by the second order analysis. The solution is sought iteratively, the calculation stops if the error is less than the chosen precision threshold of the calculation. As an error, the difference between the two deformations in the middle of the column in two following steps is chosen:

$$
\left.\epsilon=\operatorname{abs}\left(r_{N e l / 2}^{i}-r_{N e l / 2}^{i-1}\right)\right)<\epsilon_{\text {chosen }},
$$

where: $\mathrm{Nel}$ - number of elements, $\mathrm{Nel} / 2$ means middle of the column, $r$ see below, $i$ - number of steps, $\epsilon_{\text {chosen }}-$ chosen error in metres. In algorithm, 10e-07 is used.

A beam representing the column is divided into smaller elements, which have a prismatic shape - the cross section is constant over the elements' length. For the required precision, the usual number of elements is between 128 and 512. The solution is carried out in the following steps:

(1.) Finding a linear solution in the first step, calculation of internal forces.

(2.) Finding the neutral axis of each element, forming the updated matrix of cross-section properties with reduced moments of inertia $I y, I z, I y z$, areas of the cross sections and the shifts of the centroid caused by the material non-linearity.

(3.) Updating the geometry of the column, finding the solution to the set of new equations, go to the step 2 and repeat it, until the error is lower than the chosen precision threshold of the calculation. The case for which the error is growing and does not converge means a collapse of the structure.

\subsection{General equations For the solution}

The analysis of frame buckling by the stiffness method generally reduces according to 13 to a linear matrix equation:

$$
K(\mu) r=f,
$$

where: $r$ is the column matrix of small generalized displacement increments from the initial state, $f$ is a column matrix of the associated small generalized force increments, $K$ is the matrix of incremental stiffness coefficients and $\mu$ is the parameter of initial loads that are independent of $f$. Equation 1 represents a matrix eigenvalue problem of a nonstandard type, because the coefficients of $\mathrm{K}$ depend on $\mu$ non-linearly, and $\mu$ does not appear only in diagonal terms. To get rid of this non-linearity, columns are subdivided into three or more elements (in this article, the number of elements is between 128 and 512), the linear part of Taylor expansion is used, we obtain nonstandard linear eigenvalue problem:

$$
\left(K-K_{G}\right) r=0,
$$

where: $K_{G}-$ geometric stiffness matrix. The iterative solution begins with the equation:

$$
K r=f+f_{e k v}
$$

where:

$$
f_{e k v}=K_{G} r
$$

\subsection{EquATIONS USED FOR THE SOLUTION AND} THE STEP-BY-STEP SOLUTION

In the first step

$$
K r^{0}=f
$$

From which we get $r^{0}, N^{0}, K_{G}^{0}$, where: $r^{0}$ - initial displacement vector from the first step, $N^{0}$ - initial normal force from the first step, $K_{G}^{0}$ - geometric stiffness matrix, which is calculated from the initial normal force and is used in the next step. In $i$-th step of the iteration:

$$
K r^{i+1}=f+K_{G}^{i} r^{i},
$$

Convergence criterion: see Equation 19

\subsection{MATERIAL NON-LINEARITY}

For the calculation of stresses, many stress-strain diagrams can be used. In the study of non-linear behaviour of masonry columns, six basic possibilities are used, see Figure 8, the rigid plastic can be seen in Figure 9

Linear-plastic, parabolic-plastic (parabolicrectangular) and rigid-plastic diagrams are given in [1]. The ASCE diagram can be seen in [14], Augenti and Parisi can be seen in [15. The method of finding the stress distribution in the cross section consists of two iterative calculations. The cross section is divided in a final number of parts (for the final results, 300 parts were used), the stress resulting from the strain is integrated numerical and internal forces are obtained. In the first iterative calculation, the $E m$ - the multiple of modulus of elasticity is sought, to fulfil the force equilibrium condition. In case that the bending moment acting in the cross section is not equal to the bending moment obtained by integrating the stresses, the neutral axis is moved and the $E_{m}$ is sought again, until both the moment and the force equilibrium conditions are fulfilled.

This calculation is done for all elements. Then, the $(i+1)$-th step (further step) of the calculation according to section 3.4 is carried out. This step is repeated, until the convergence criterion is fulfilled. In each step, the strain is controlled. 


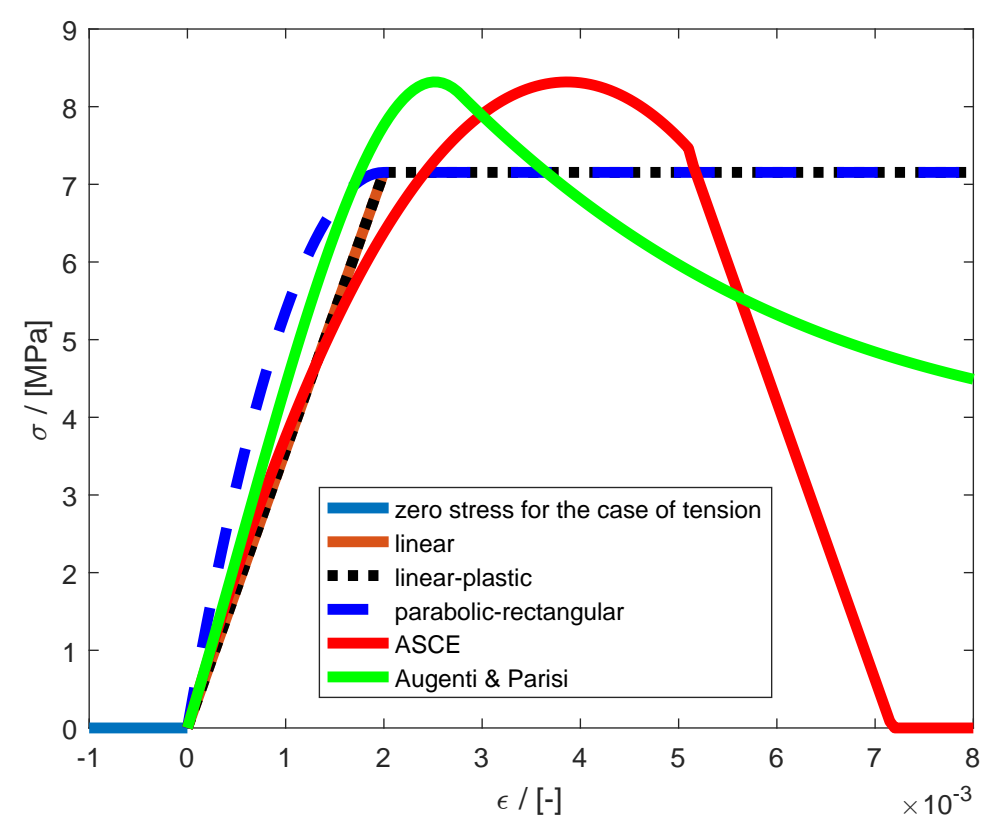

Figure 8. Various stress-strain diagrams.

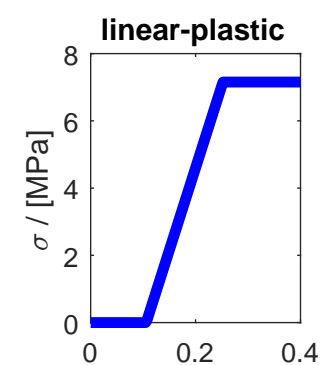

$\mathrm{H} /[\mathrm{m}]$

Augenti \& Parisi - parab.

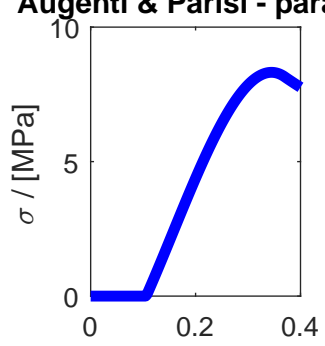

$\mathrm{H} /[\mathrm{m}]$

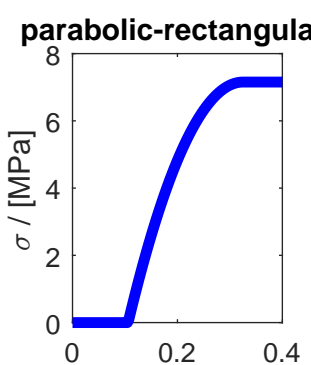

$\mathrm{H} /[\mathrm{m}]$

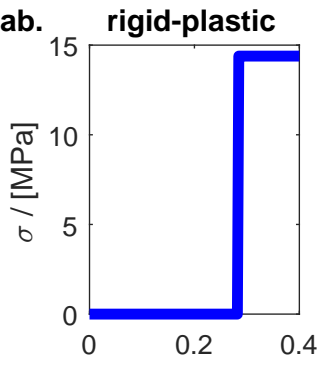

$\mathrm{H} /[\mathrm{m}]$
ASCE - parabolic

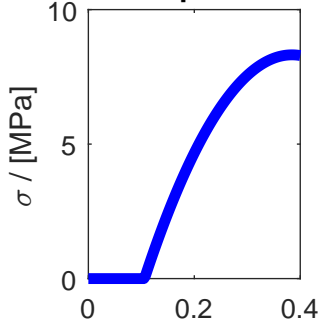

$\mathrm{H} /[\mathrm{m}]$

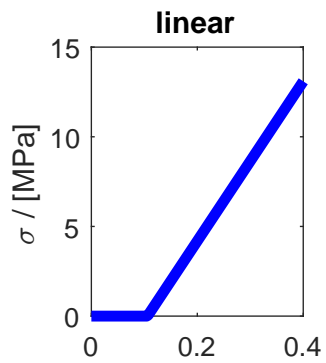

$\mathrm{H} /[\mathrm{m}]$

FiguRE 9. Resulting stress for various stress-strain diagrams, $B \times H=0.4 \times 0.4 \mathrm{~m}, \mathrm{~N}=670 \mathrm{kN}, \mathrm{M}=95 \mathrm{kNm}$. 


\section{Results OF MODELLing}

The results can generally be divided into 3 cases:

(1.) Short columns - just 2 steps of calculation are enough to fulfil the criterion according to 19 The failure occurs due to material crushing (overstress).

(2.) Long columns, for which the finite number of steps is enough to fulfil the convergence criterion and the stress doesn't exceed the tensile strength (which is considered zero). The failure occurs due to material crushing (the bending moments increased by slenderness).

(3.) Slender columns, where the material non-linearity impacts the result, because the tensile strength is exceeded. The failure occurs because of buckling.

In this chapter, the results of modelling of a single column are presented as well as a study of a relevant set of columns, which shows how the 3D effects, material non-linearity and geometric non-linearity impact the stability and the resistance of the masonry column.

\subsection{EXAmple OF Single COLUmN}

To demonstrate an example, a column of a height of $5 \mathrm{~m}$ is chosen. The dimensions of the column are $B \times$ $H=0.5 \times 0.3 \mathrm{~m}$. Eccentricity (initial imperfection) is chosen as $e_{y}=0.15 b$, eccentricity $e_{z}=0.025 H, f_{k}=$ $6.42 M P a, E=1000 f_{k}$.

\subsection{STUdy OF VARIOUS COLUMNS}

The ACI approach [7] is compared to the result of modelling used in this article (named "Mason"). According to the ACI, the stress in all points of the cross section must be negative (compression). Second order moments should be included. In the study, column thickness $B$ was chosen $0.4 \mathrm{~m}$ and $H$ was variable, as well as slenderness $\lambda_{s}$. Eccentricities were chosen the same as in the example above.

For the purpose of showing the effect of using various stress-strain diagrams, the following example is used. A cross section with dimensions $B \times H=$ $0.4 \times 0.4 \mathrm{~m}$ is loaded with the force $N_{E d}=670 \mathrm{kN}$ and various bending moments. After the convergence of an iteration of the bending moment is fulfilled, a different height of the compressed area was found for the various stress-strain diagrams, see Figure 16

Due to a different resulting height of the compressed area, the final carrying capacity varies for the various stress-strain diagrams. Note that the carrying capacity is limited by the slenderness (and second-order effect) as well as the stress limitation according to the stress-strain digram (see the Figure 8 and 9 ). The limit stress, which should not be exceeded, is considered as $f_{k}$ for all the stress-strain diagrams for the reason of comparability, except for the ASCE and Augenti \& Parisi diagrams, for which the maximal stress is equal to $f_{k} / 0.86$.

It can be seen from the Figure 17 that the resulting curve, due to the ACI requirements, is quite similar to curve representing the linear behaviour. This is because of the fact that the considered eccentricities are the same for all the cases and the decisive criterion was always criterion of maximal stress, not the crack opening. For different eccentricities, the curves would vary.

\section{Comparing the RESUlts FROM the EXPERIMENT}

The experiment, described in [16, was based on testing 5 columns with a height of $2.75 \mathrm{~m}$ loaded by a force and an eccentricity in one horizontal direction (denoted "1e") and 5 columns with a height of $1.75 \mathrm{~m}$ loaded by a force and an eccentricity in two horizontal directions (denoted "2e"). Dimensions of the columns are $B \times H=0.44 \times 0.5 \mathrm{~m}$. The specimen 1 was tested in a centric compression, the design stress $f_{d e}$ was taken from this specimen 1 and considered for the other specimens. The following expression was used:

$$
f_{d e}=\frac{N_{m, A 2}}{B H},
$$

where: $f_{d e}$ - the strength of specimen 1 , which is used for other specimens, $N_{m, A 2}$ - the normal force, at which the crushing of specimen 1 occurred.

The bricks tested are usually used in new masonry walls and they have cavities due to the requirements of energy codes. As it can be seen from Figure 18 the curves obtained by measuring the strain by strain gauges are linear for the whole duration of the experiment. According to [16], "the way of deforming can be described as quasi-linear, mode of failure is brittle and the crushing always occurred at the outer edge, closer to the applied force" which means, that a collapse of a one face of a brick means stopping further loading. The collapse is always caused by the combination of a normal force and bending moment and the point of failure was always a collapse of a one face of a brick.

In Table 1 a new check is added for the comparison. In this check, "Mason - lin. Diagram -> rigid plastic check", the normal force of resistance in the ULS $N_{R d}$ is calculated in the following manner: internal forces and the shape of the cross section was taken from the linear stress-strain diagram (see the example of stress-strain diagram in Figure 11). Then, the resulting effective cross section is loaded by the force with eccentricities calculated from the acting bending moments - the forces from the linear calculation are checked by the rigid-plastic check of the ULS. 


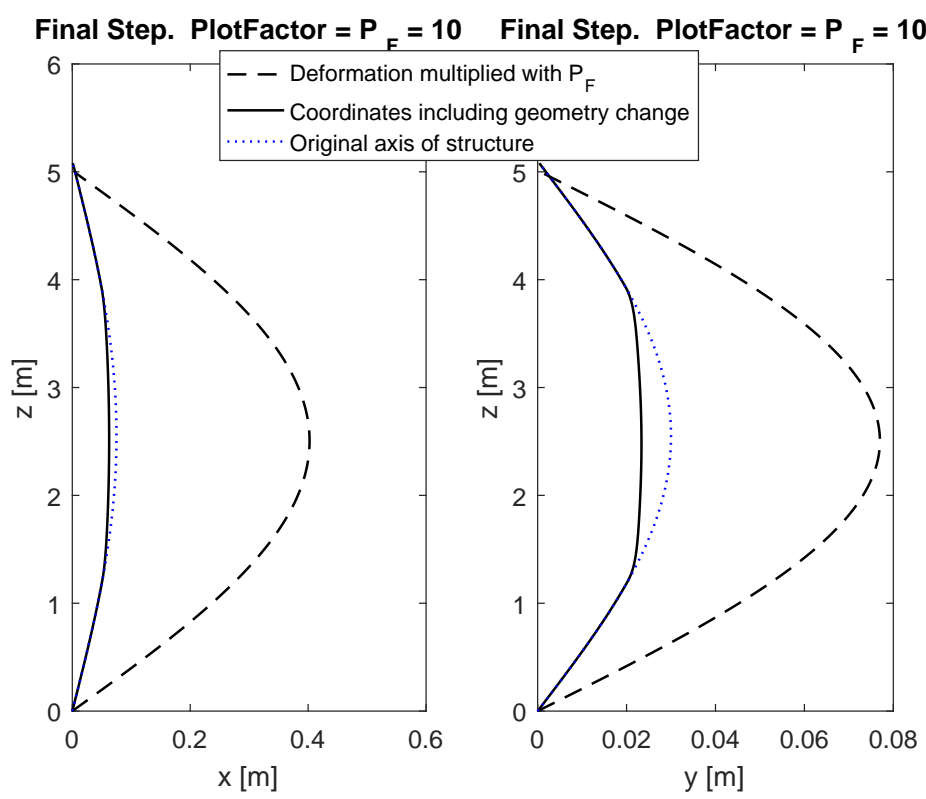

FigURE 10. Final geometry in global coordinate system $x_{g}, y_{g}$.

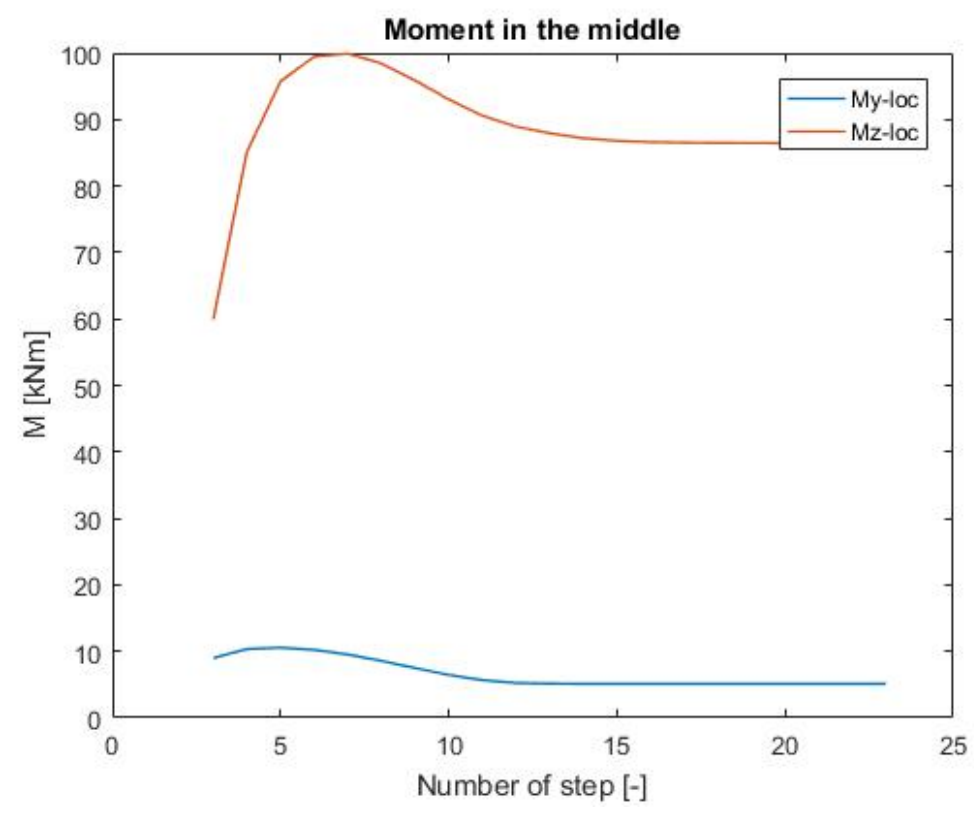

Figure 11. Moment convergence. 

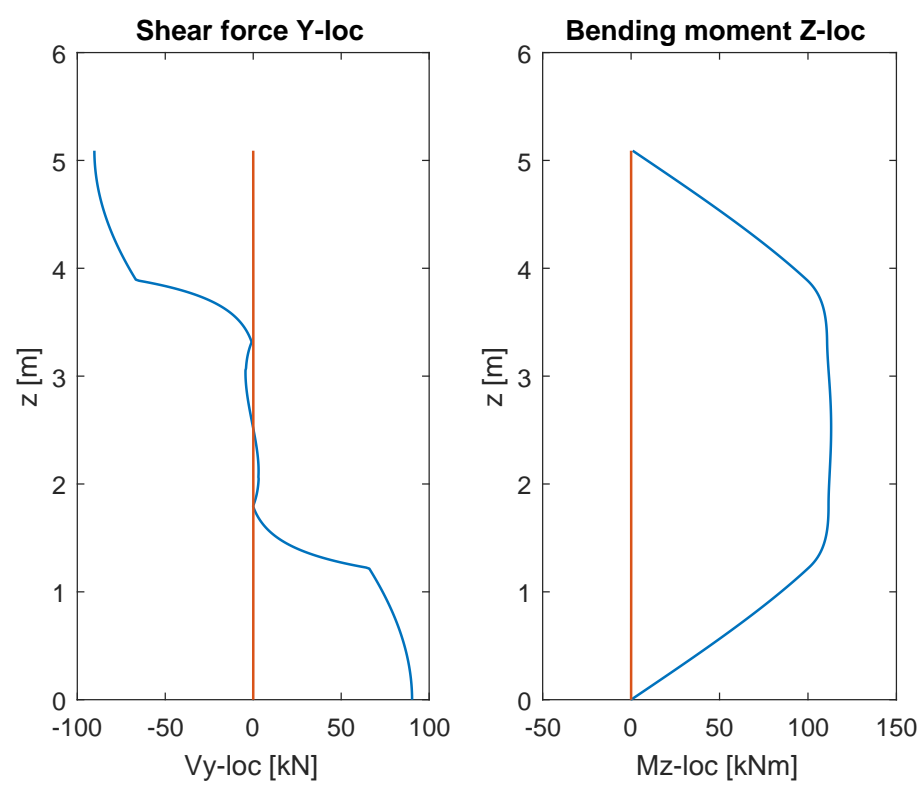

FiguRE 12. Final internal forces - bending moment and shear force.

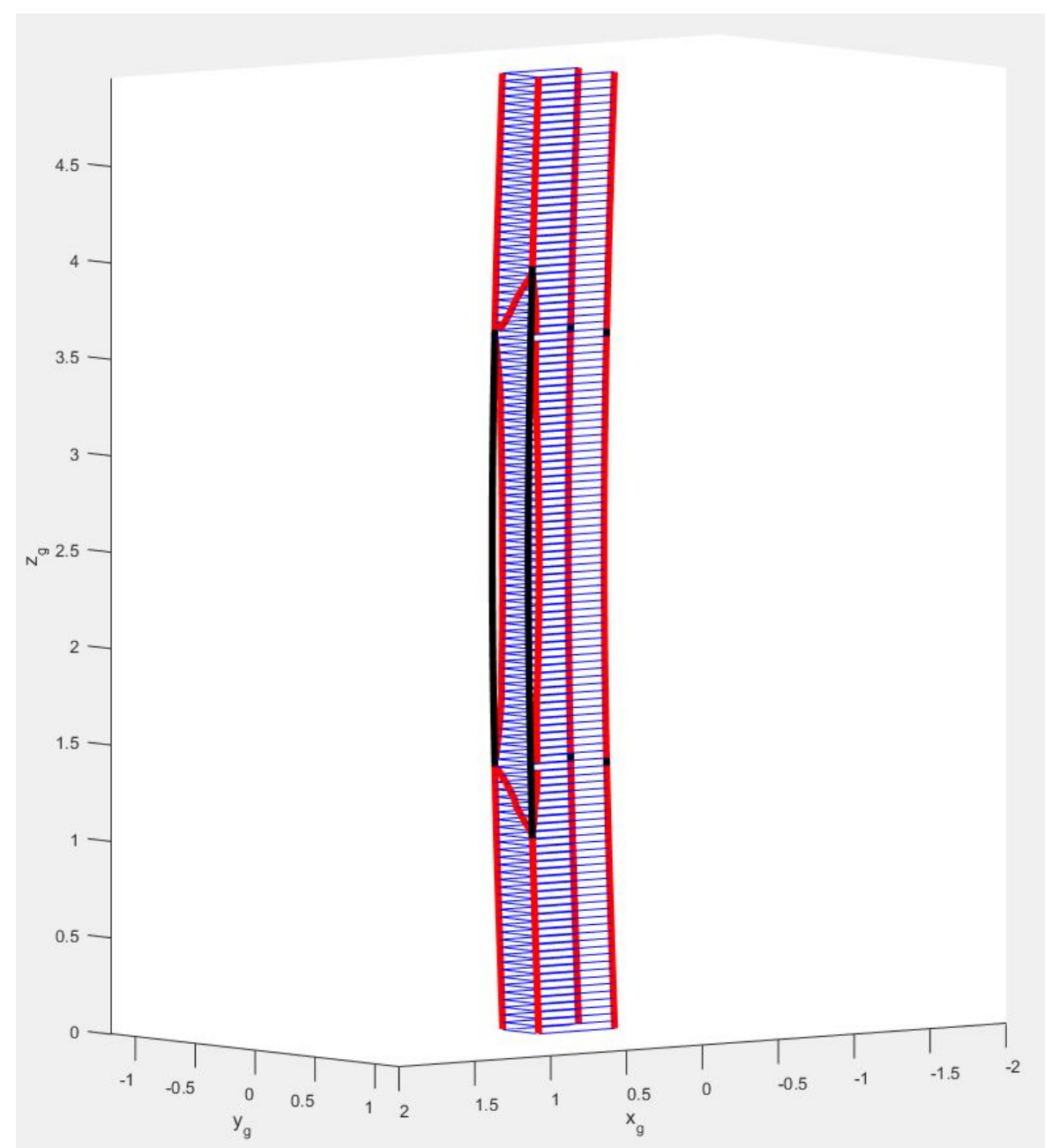

FIGURE 13. Final shape of column (excluding tensioned parts) in global coordinate system. 


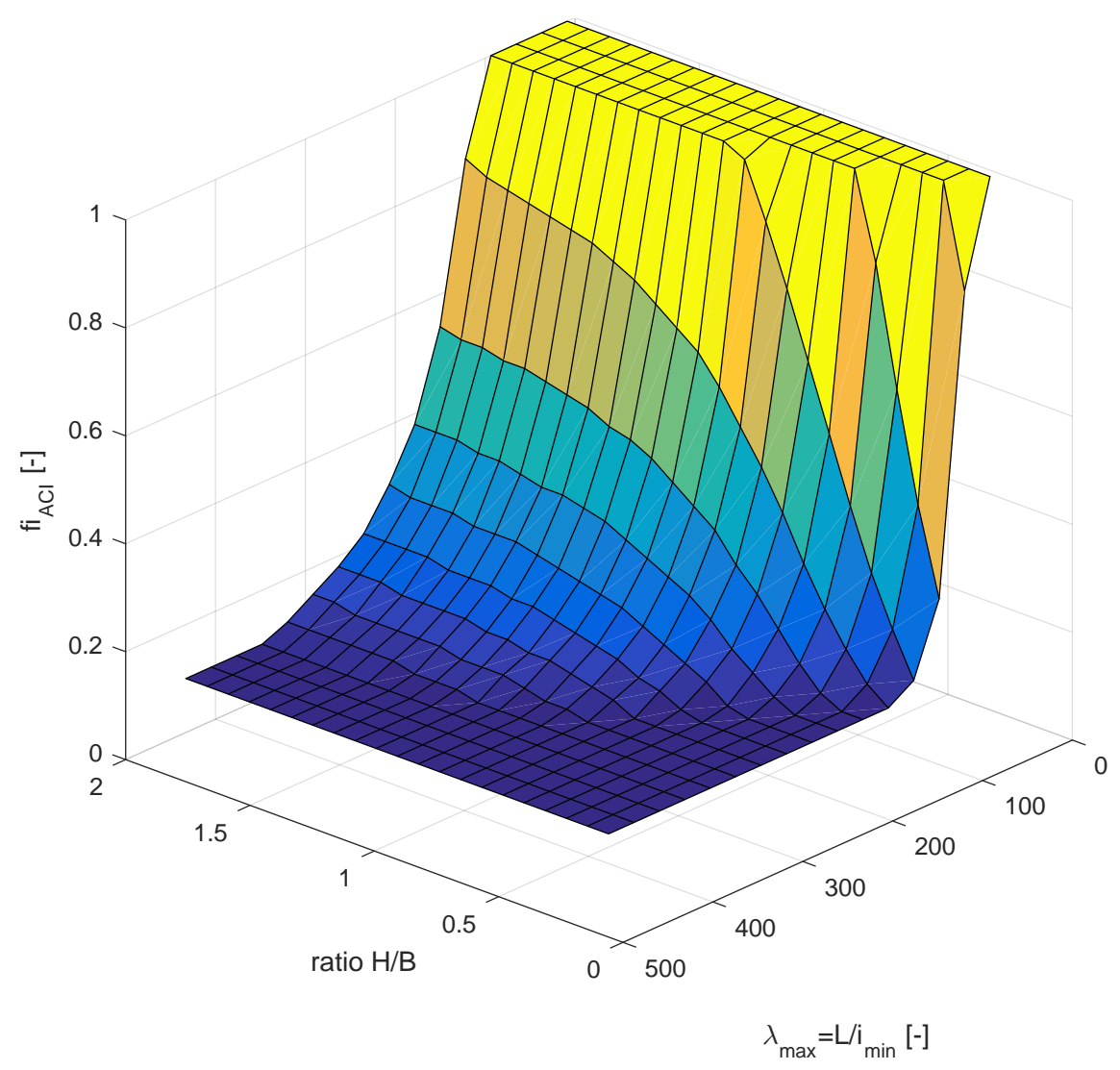

Figure 14. Slenderness reduction factor $f i=\Phi$ from the algorithm, using the ACI approach.

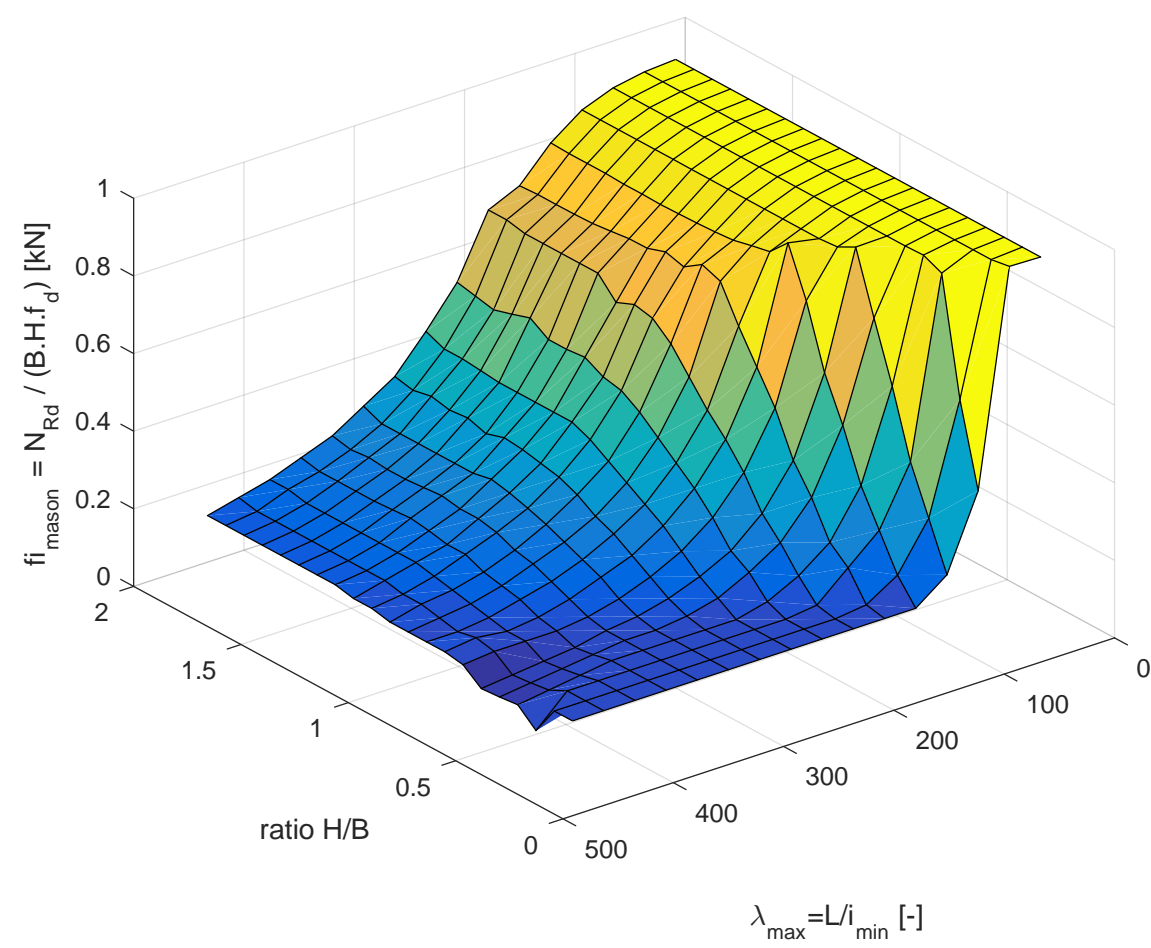

FiguRE 15. Slenderness reduction factor $f i=\Phi$ from the algorithm, using the "Mason" approach. 


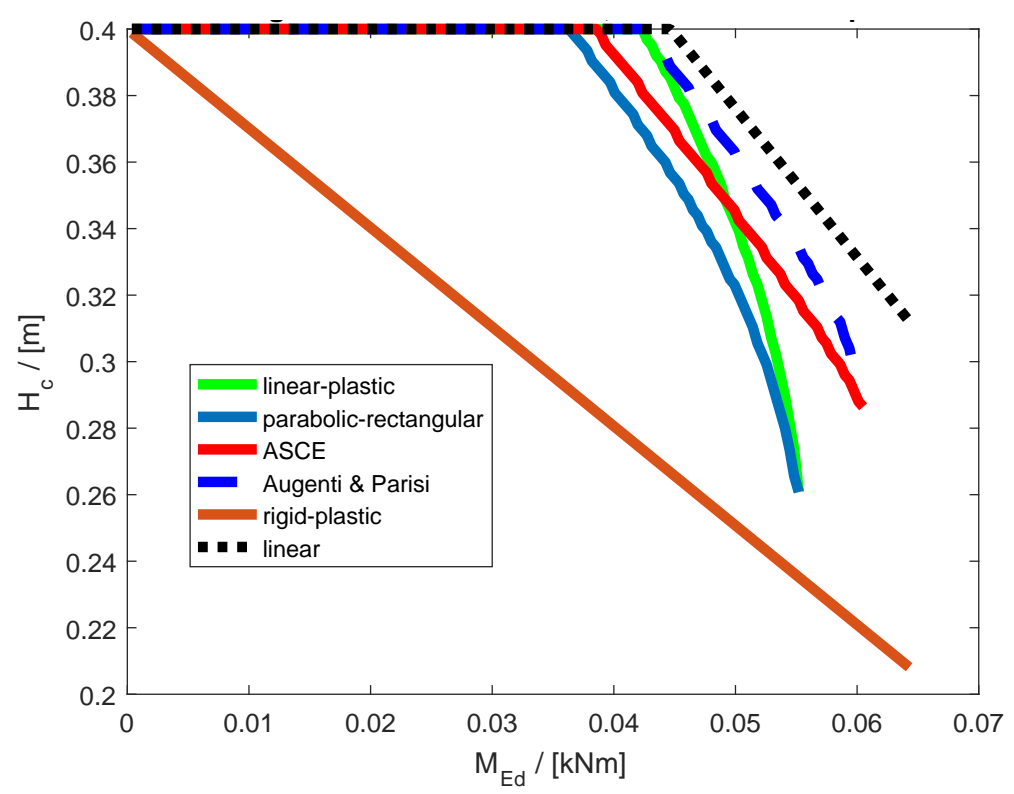

FIGURE 16. Comparing the resulting heights of cross sections from various stress-strain diagrams.

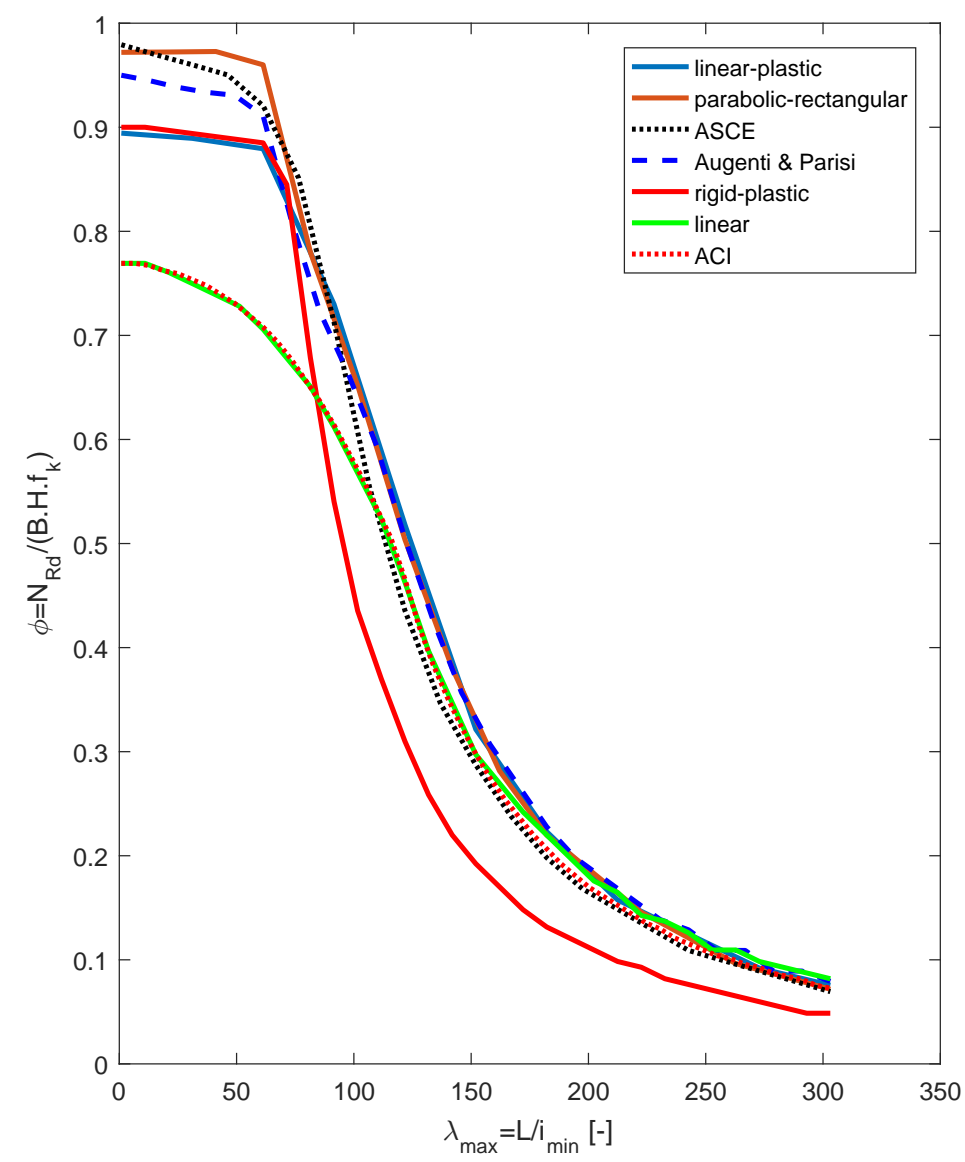

FiguRE 17. Comparing the final slenderness reduction factor from various stress-strain diagrams. 


\begin{tabular}{|c|c|c|c|c|c|}
\hline \multicolumn{6}{|c|}{ experiment 1e } \\
\hline specimen & $1-0$ & $1-1$ & $1-2$ & $1-3$ & $1-4$ \\
\hline \multicolumn{6}{|l|}{ Quantity name } \\
\hline eccentricity $e_{z}[\mathrm{~m}]$ & 0 & 0.072 & 0.147 & 0.11 & 0.11 \\
\hline eccentricity $e_{y}[\mathrm{~m}]$ & 0 & 0 & 0 & 0 & 0 \\
\hline Max.force $N_{m}[\mathrm{kN}]$ & 1207 & 992.0 & 577.0 & 717.0 & 759.0 \\
\hline \multicolumn{6}{|c|}{ EN1996 - rigid-plastic check (rec. shape) } \\
\hline$A 1_{z}[-]$ & 1 & 0.673 & 0.332 & 0.5 & 0.5 \\
\hline$A 2_{y}[-]$ & 1 & 1 & 1 & 1 & 1 \\
\hline$A c[-]$ & 0.22 & 0.148 & 0.073 & 0.11 & 0.11 \\
\hline$u 1[-]$ & 0.237 & 0.322 & 0.512 & 0.397 & 0.397 \\
\hline$\phi 1[-]$ & 0.972 & 0.950 & 0.877 & 0.924 & 0.924 \\
\hline$\phi 2[-]$ & 1.000 & 1.000 & 1.000 & 1.000 & 1.000 \\
\hline$N R d[\mathrm{kN}]$ & 1207 & 793 & 361.3 & 573.8 & 573.8 \\
\hline \multicolumn{6}{|c|}{ Mason, lin. diagram -> rigid-plastic check (rec. shape) } \\
\hline$N R d[\mathrm{kN}]$ & 1224 & 818.2 & 377.0 & 581.9 & 581.9 \\
\hline \multicolumn{6}{|c|}{ Mason, rigid-plastic diagram and check (rec. shape) } \\
\hline$N R d[\mathrm{kN}]$ & 1210 & 825.1 & 407 & 613.3 & 613.3 \\
\hline
\end{tabular}

TABLE 1. Uni axial bending experiment " $1 \mathrm{e}$ ".

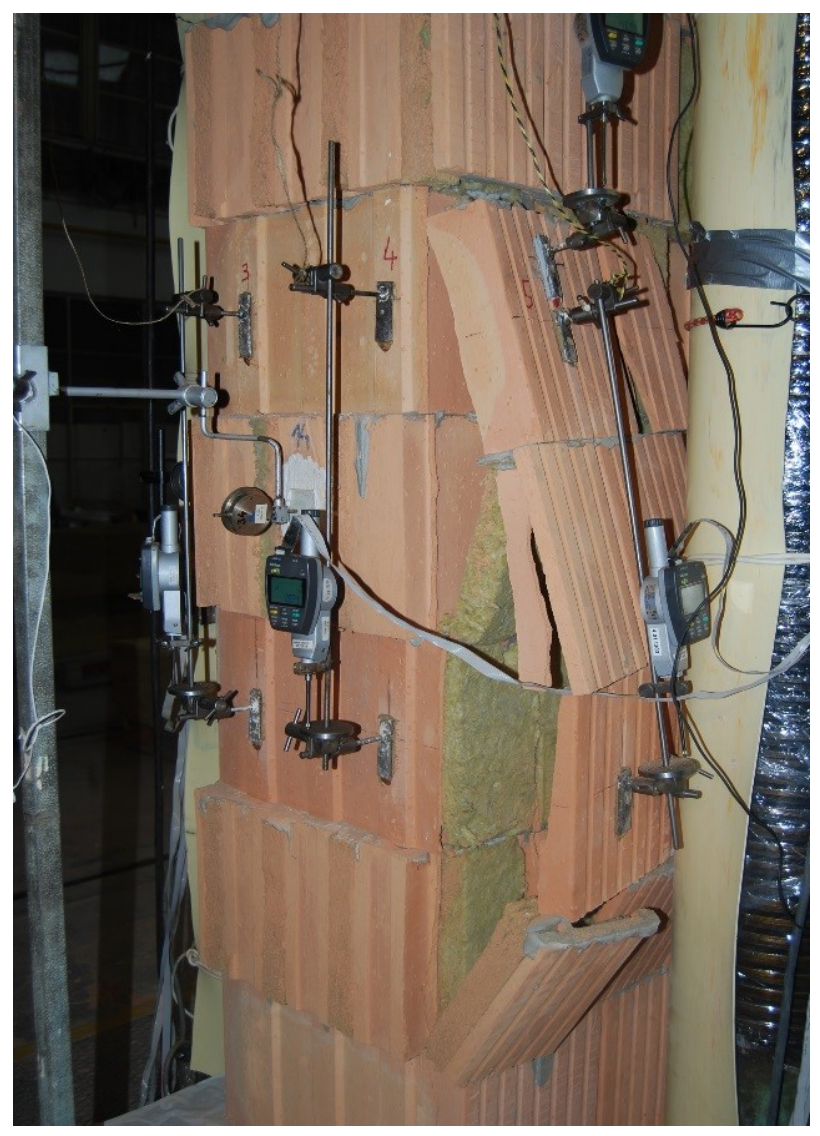

FIGURE 18. The detail of failure of specimen loaded by force with eccentricities in two directions.

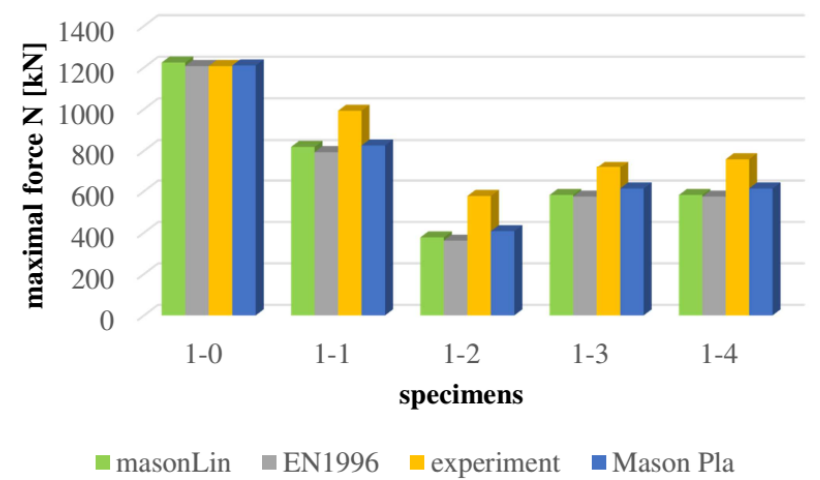

Figure 19. The graphical expression of maximal forces of "1e".

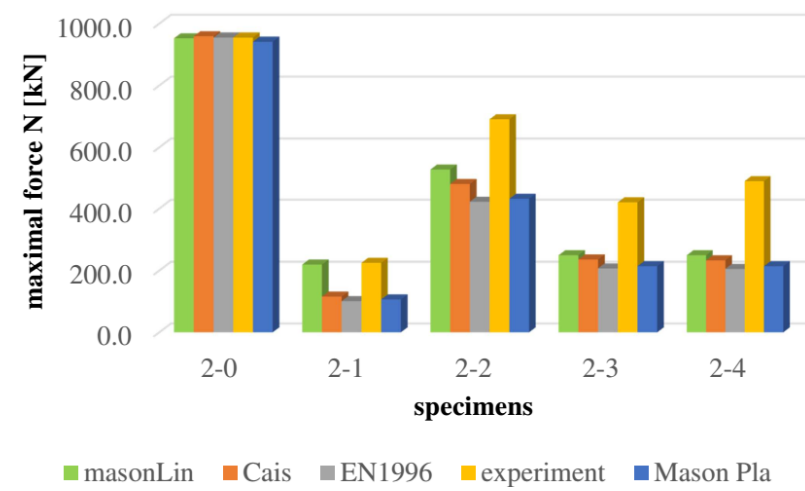

Figure 20. The graphical expression of maximal forces of " $2 \mathrm{e}$ ". 


\begin{tabular}{|c|c|c|c|c|c|}
\hline \multicolumn{6}{|c|}{ experiment $2 \mathrm{e}$} \\
\hline specimen & $2-0$ & $2-1$ & $2-2$ & $2-3$ & $2-4$ \\
\hline \multicolumn{6}{|l|}{ Quantity name } \\
\hline eccentricity $e_{z}[\mathrm{~m}]$ & 0 & 0.147 & 0.073 & 0.073 & 0.147 \\
\hline eccentricity $e_{y}[\mathrm{~m}]$ & 0 & 0.167 & 0.08 & 30.167 & 0.083 \\
\hline Max.force $N_{m}[\mathrm{kN}]$ & 955 & 225 & 691 & 420 & 488 \\
\hline \multicolumn{6}{|c|}{ EN1996 - rigid-plastic check (rec. shape) } \\
\hline$A 1_{z}[-]$ & 1 & 0.332 & 0.668 & 0.668 & 0.332 \\
\hline$A 2_{y}[-]$ & 1 & 0.332 & 0.668 & 0.332 & 0.668 \\
\hline$A c[-]$ & 0.22 & 0.024 & 0.098 & 0.049 & 0.049 \\
\hline$u 1[-]$ & 0.12 & 0.258 & 0.163 & 0.163 & 0.258 \\
\hline$u 2[-]$ & 0.095 & 0.205 & 0.129 & 0.205 & 0.129 \\
\hline$\phi 1_{z}[-]$ & 0.993 & 0.967 & 0.987 & 0.987 & 0.967 \\
\hline$\phi 2_{y}[-]$ & 0.996 & 0.979 & 0.992 & 0.979 & 0.992 \\
\hline$N R d[\mathrm{kN}]$ & 955 & 100.8 & 422 & 207.1 & 205.4 \\
\hline \multicolumn{6}{|c|}{ Cais, J. - rigid-plastic check (general shape) } \\
\hline$\lambda[-]$ & 1.5 & 0.498 & 1.002 & 1.002 & 0.498 \\
\hline$\beta[-]$ & 1.5 & 0.498 & 1.002 & 0.498 & 1.002 \\
\hline$\lambda \cdot B[\mathrm{~m}]$ & & 0.219 & 0.441 & 0.441 & 0.219 \\
\hline$\beta \cdot H[\mathrm{~m}]$ & & 0.249 & 0.501 & 0.249 & 0.501 \\
\hline$N R d[\mathrm{kN}]$ & 959.3 & 115.8 & 478.8 & 236.1 & 233 \\
\hline \multicolumn{6}{|c|}{ Mason, lin. diagram -> rigid-plastic check (rec. shape) } \\
\hline$N R d[\mathrm{kN}]$ & 952.6 & 219.6 & 528.5 & 249.7 & 249.5 \\
\hline \multicolumn{6}{|c|}{ Mason, rigid-plastic diagram and check (rec. shape) } \\
\hline$N R d[\mathrm{kN}]$ & 941.6 & 106.4 & 431.3 & 214.3 & 214.2 \\
\hline
\end{tabular}

TABLE 2. Uniaxial bending experiment " $2 \mathrm{e}$ ".

It can be seen that for all the cases, the results from the "Mason" calculation are closer to the results obtained from the experiment than the resistance according to the current standard EN1996. It should be noted that more experiments should be carried out and columns in the experiments should be more slender.

Mathematical modelling was also part of the article [16]. The author used 3D FEM model using 3D solid elements with a non-linear behaviour - a modified Drucker-Prager model was chosen. The shortcut of this method is MN-S. It was stated that "computational models compared to the results of experiments reflect very well the behaviour of the tested masonry pillars and bodies as well as the way of their deformation and failure".

\section{Results Discussion}

All the methods used in the mentioned literature review have at least one error. Mostly, it is the assump- tion of a rigid-plastic behaviour, which we consider incorrect (see below). The use of a real stress-strain diagram leads to methods, which can't be used for a practical design. For example, article [16] deals especially with the preciseness of modelling of the boundary conditions - especially the supporting sheet metal of the compression testing machine. In a case of a practical design, these conditions are unknown, and therefore the 3D solid non-linear time-demanding and tough method seems to be impracticable. The calculation according to the ACI gives the same results, for small bending moments (small eccentricities, such as eccentricities chosen in the study of this article), as the non-linear calculation, because the tension doesn't occur until the collapse of the column. However, the ACI approach is conservative, because a larger bending moment, which causes tension, is not admitted.

The verification of a normal loading capacity provided in the current standard [1] by using the rigid- 


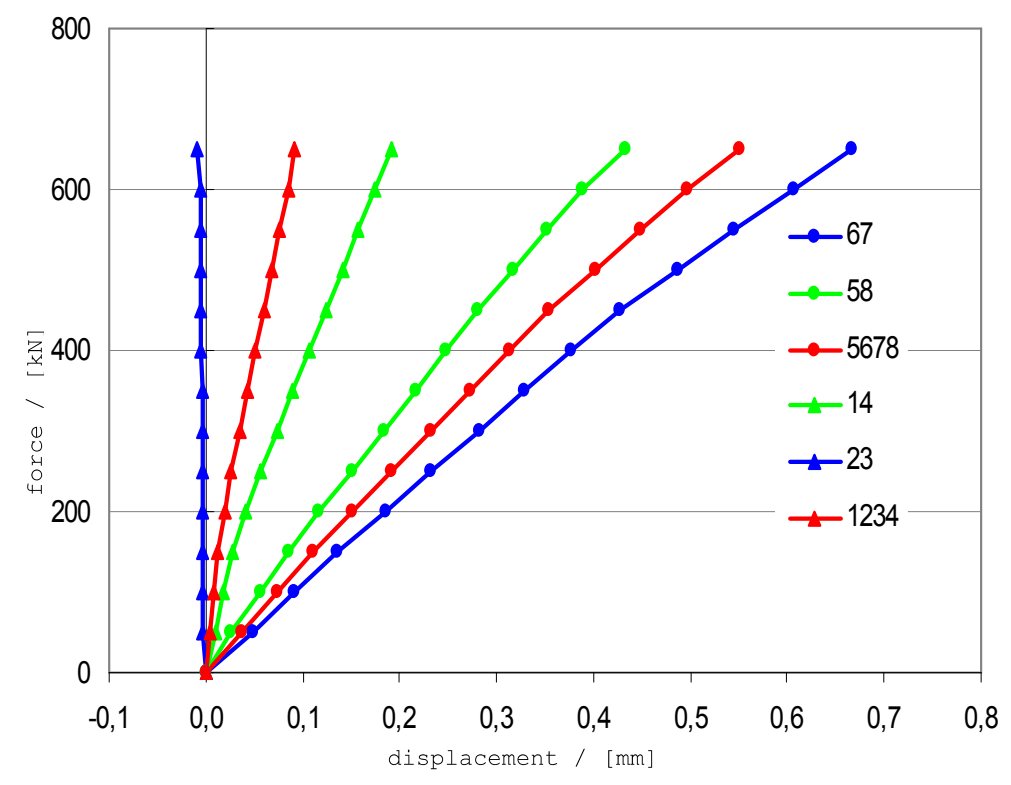

Figure 21. Typical strain on the perimeter of the pier.

plastic stress-strain diagram is insufficient for a $3 \mathrm{D}$ case. Handling the 3D case by calculating the eccentricities from the equilibrium conditions and using the equation, which is also used to verify the shallow foundation of rectangular shape, we get:

$$
N_{E d} \leq N_{R d}=\left(B-2 e_{y}\right)\left(H-2 e_{z}\right) f_{d},
$$

This formula also assumes the fully rigid-plastic behaviour. This can theoretically occur in the case of an infinite rotation of the cross section. This cannot obviously be considered for the slender columns, it would result in an infinite deformation and, in the used second order beam analysis, infinite acting bending moment and a collapse of the structure. The results of calculating the compressed area using the equation 27 without controlling the strain can be seen in the Figure 17. The height of the compressed area is much lower than in the other stress-strain diagrams. For this reasons, we do not recommend the rigidplastic stress-strain diagram for analysing the slender masonry columns.

From Figure21, it can be seen that the function of the strain is more or less linear (until the failure). Also, according to [17, the behaviour in experiments fits best to the linear behaviour of material.

Also, comparing the results of experiments with various calculation methods showed a good accordance of the normal resistance force obtained by the linear calculation and by the experiment.

Based on the previous paragraphs, we recommend to verify the slender column's loading capacity, in terms of the ULS and the SLS, by using a linear stress-strain diagram for the practical design. The difference between the ULS and SLS should only be in the value of the coefficients $\gamma_{M}, \gamma_{F}$ used (see the explanation in [1]). The method for calculating the internal forces should include the material and geometric non-linearity. The area of the cross section, which remains after the reduction by the material non-linearity and after fulfilling the convergence criterion, was at minimum $50 \%$ in this study. This tally well enough with standard [18]. This standard recommends to limit eccentricity to $e \leq h / 3$ in the SLS, the author of this article recommends to also use this limit for the ULS, i.e., to use the relation:

$$
H_{\text {compressed }} \geq H / 2 \rightarrow e \leq H / 3,
$$

for the uniaxial bending and

$$
A_{\text {compressed }} \geq A / 2,
$$

for a biaxial bending ( $A$ - total area of cross section). This recommendation fits for slender columns, $\lambda_{s}>10$. For short masonry elements, loaded by a force with large eccentricity, which significantly reduces the effective area, the author of this article recommends to analyse the column as a new column with a reduced - effective area, i.e., to use the effective dimensions of the column for the calculation of $u$ and $\lambda$, not the original ones.

Article [19] recommends to modify the equation 28 in dependence on a category of the masonry (categories are defined in [1]), namely to limit the maximal eccentricities in the ULS to $0.45 H$ for category 1 and to $0.4 H$ for category 2 .

The shear criterion of the resistance according to [1:

$$
V_{E d} \leq V_{R d}=\left(f_{v k, 0}+0.4 \sigma_{d}\right) b\left(H-2 e_{u}\right) / \gamma_{M},
$$

where: $V_{E d}$ - shear force from the load, $V_{R d}$ - shear resistance force, $f_{v k, 0}$ - characteristic initial shear strength of masonry under zero compressive stress, $\sigma_{d}$ 
- design compressive stress, $e_{u}$ - eccentricity of the load.

Equation 30 used for columns loaded in two planes should be replaced with the following formula:

$$
V_{E d, 3 D} \leq V_{R d}
$$

where:

$$
V_{E d, 3 D}=\sqrt{V_{E d, y}^{2}+V_{E d, z}^{2}},
$$

$V_{E d, y}, V_{E d, z}$ are shear forces from the load in the direction of axes $y, z$ respectively.

The results of the experiment showed that the nonlinear model used in this article is closer to the result of the experiment than the approach of the standard. It is obvious that the number of the specimen tested in the experiment is not enough for setting a new detailed criteria of calculating the load capacity of slender columns. Slenderness ratio $\lambda_{s}$ for the experiment, "1e" it is 21.65 , for the experiment " $2 \mathrm{e}$ " is 13.78 . Both ratios are lower than 27 , which shows that the investigated columns are not very slender. The further experiments should test a larger number of columns of various degrees of slenderness.

\section{Conclusions}

A mathematical method of verifying the slender masonry column was proposed. The method was implemented in Matlab and a study of resistance of various columns was carried out. Then, the results from the mathematical modelling were compared to the results of the experiments. Methods used in a literature were also compared. According to the combination of this methods, it was stated that the method of the currently valid standard - Eurocodes - is not suitable for the slender masonry column check. The results of a loading capacity of columns obtained by the calculation according to the standards are conservative. The behaviour of slender masonry columns with various stress-strain diagrams is quite similar, except for the rigid-plastic model, which was stated as unsuitable. Based on the previous sections, new recommendations for the design of columns were made. A second order analysis should obviously be used, linear stressstrain diagram can be used for the compression (tensile strength neglected). The compressed area should be at least one half of the total area of the cross section.

\section{REFERENCES}

[1] D. Pume, K. Lorenz. En 1996-1-1 - design of masonry structures. Standard, ÚNMZ, 2007.

[2] BSI. 5628-1:2005 Code of practice for the use of masonry, Part 1: Structural use of unreinforced masonry. Standard, British Standards Institution, 2005. DOI:10.3403/BS5628.
[3] B. Das. Principles of foundation engineering. Cengage, 2018.

[4] W. Jäger. Mauerwerk-Kalender 2012, Schwerpunkt: Eurocode 6. Ernst und Sohn, 2013. DOI:10.1002/9783433601617.ch18

[5] V. Förster. Load-bearing capacity of slender unreinforced masonry compression members under biaxial bending. Mauerwerk 21(5):320-331, 2017. DOI:10.1002/dama.201700015

[6] J. Cais. The eccentrical loading of columns in accordance with new standards. Inženýrské stavby (5), 1957.

[7] TMS 402/ACI 530/ASCE 5 - Building code requirements for masonry structures. Standard, The masonry society, 2013.

[8] M. Vokál, M. Drahorád. Non-linear analysis of slender masonry beam. Transactions of the $V \check{S} B$ 17(1), 2017. DOI:10.1515/tvsb-2017-0039

[9] G. Milani, P. Lourenco, A. Tralli. Homogenization approach for the limit analysis of out-of-plane loaded masonry walls. Journal of Structural Engineering-asce 132, 2006.

DOI:10.1061/(ASCE)0733-9445(2006)132:10(1650).

[10] E. Gazzola, R. Drysdale, A. Essawy. Bending of concrete masonry walls at different angles to the bed joints. In Proceedings 3th North American Masonry Conference, Arlington, Texas, USA, vol. 27. 1985.

[11] C. Southcombe, I. May, V. Chong. The behaviour of brickwork panels with openings under lateral load. In Proceedings of the British Masonry Society, vol. 7, pp. 105 - 110. 1995.

[12] S. Timoshenko, J. Gere. Theory of Elastic Stability. McGraw-Hill., 1961.

[13] Z. P. Bažant, L. Cedolin. Stability of structures; Elastic, inelastic fracture and damage theories. World Scientific Publishing Co. Pte. Ltd., 2010.

[14] B. H. Kaushik, C. D. Rai, S. K. Jain. Stress-strain characteristics of clay brick masonry under uniaxial compression. Journal of Materials in Civil Engineering 19(9), 2007. DOI:10.1061/ASCE0899-1561200719:9728

[15] N. Augenti, F. Parisi. Constitutive models for tuff masonry under uniaxial compression. Journal of Materials in Civil Engineering 22(11), 2010. DOI:10.1061/(ASCE)MT.1943-5533.0000119

[16] J. Klouda. The behavior of masonry columns loaded eccentrically, part 1 and 2. Stavebnictví (8), 2016.

[17] L. Z. Hansen. Stability of Masonry Columns. Danmarks tekniske universitet, 2003.

[18] V. Hrdoušek, M. Drahorád. Čsn p 736213 - design of masonry road bridges. Standard, ÚNMZ, 2008.

[19] V. Honzík, M. Drahorád. The behavior of masonry columns loaded eccentrically. Stavebnictví (4), 2017. 